\title{
Successful non-surgical treatment on bilateral spontaneous perirenal giant hematomas in rapidly progressive
} glomerulonephritis with MPO-ANCA positive

\author{
Yuri Nakashima', Maki Ohura ${ }^{1,2}$, Toru Mima ${ }^{1 *}$, Asuka Masumoto ${ }^{1}$, Masaki Ohya', Shigeo Negi ${ }^{1}$ \\ and Takashi Shigematsu ${ }^{1}$
}

\begin{abstract}
Background: Perirenal hematomas are most frequently caused by neoplasm, followed by polyarteritis nodosa (PN), but may also be a rare complication of MPA.

Case Presentation: A 77-year-old woman who presented with rapidly progressive glomerulonephritis, proteinuria, and mononeuropathy multiplex, and was positive for serum myeloperoxidase-anti-neutrophil cytoplasmic antibody, was diagnosed with vasculitis as a probable microscopic polyangiitis (MPA). She developed a spontaneous right-sided perirenal hematoma, along with back pain, on the day of referral to the nephrology unit and a spontaneous left-sided perirenal hematoma ten days later. Treatment with $30 \mathrm{mg} /$ day prednisolone stabilized the hematomas and controlled the progression of probable MPA.

Conclusion: Nephrectomy or embolization is commonly required in patients with perirenal hematoma associated with neoplasm or PN, but radical invasive management may not be necessary in patients with MPA because smaller blood vessels are affected, resulting in less extensive bleeding and normal clotting. Accurate differential diagnosis between MPA and PN is essential to avoid invasive management of perirenal hematomas in patients with MPA. The presence of glomerulonephritis suggests injury to capillary vessels, a characteristic of MPA.
\end{abstract}

Keywords: Spontaneous perirenal hematoma, Microscopic polyangiitis, Polyarteritis nodosa, Non-surgical treatment

\section{Background}

Microscopic polyangiitis (MPA) can be distinguished from polyarteritis nodosa $(\mathrm{PN})$ by the size of affected vessels [1]. MPA is defined as pauci-immune necrotizing vasculitis affecting small vessels, with or without involvement of medium-sized arteries, whereas PN is defined as arteritis of small- and medium-sized arteries without involvement of smaller vessels. However, the clinical manifestations of MPA and PN are similar. Spontaneous perirenal hematoma is not uncommon in patients with $\mathrm{PN}$, but is rare in patients with MPA. Aggressive treatment,

\footnotetext{
*Correspondence: mimat@wakayama-med.ac.jp

'Division of Nephrology, Department of Internal Medicine, Wakayama Medical University, 811-1 Kimiidera, Wakayama, Wakayama 641-8509, Japan Full list of author information is available at the end of the article
}

including embolization, is sometimes necessary for perirenal hematoma in patients with PN, but the optimum treatment of perirenal hematomas in patients with MPA remains undetermined.

This report describes a patient with vasculitis as a probable MPA and bilateral spontaneous perirenal hematomas, as well as her treatment and outcome.

\section{Case presentation}

A 77-year-old woman experienced neck pain, weakness in both arms, and nocturnal fever, followed 1 month later by leg edema and palsy, gait disorder, and pain in the arms. Two months after, she first felt ill; her family doctor diagnosed her with polymyalgia rheumatica and prescribed $10 \mathrm{mg} /$ day prednisolone (PSL). Her renal function was 
Table 1 The data of blood and urinary sediment examination at the nephrology referral

\begin{tabular}{|c|c|}
\hline Parameter & Value \\
\hline \multicolumn{2}{|l|}{ Peripheral blood } \\
\hline Red blood cells & $317 \times 10^{\wedge} 4 / \mu \mathrm{L}$ \\
\hline Hemoglobin & $8.6 \mathrm{~g} / \mathrm{dL}$ \\
\hline Hematocrit & $26.50 \%$ \\
\hline White blood cells & $18200 / \mu \mathrm{L}$ \\
\hline Neutrophil & $86.00 \%$ \\
\hline Monocyte & $9.00 \%$ \\
\hline Lymphocyte & $3.00 \%$ \\
\hline Platelet & $32.5 \times 10^{\wedge} 4 / \mu \mathrm{L}$ \\
\hline \multicolumn{2}{|l|}{ Blood chemistry } \\
\hline Total protein & $4.7 \mathrm{~g} / \mathrm{dL}$ \\
\hline Total bilirubin & $1.0 \mathrm{mg} / \mathrm{dL}$ \\
\hline AST & $44 \mathrm{IU} / \mathrm{L}$ \\
\hline ALT & $38 \mathrm{IU} / \mathrm{L}$ \\
\hline LDH & $360 \mathrm{IU} / \mathrm{L}$ \\
\hline CK & $102 \mathrm{IU} / \mathrm{L}$ \\
\hline Total cholesterol & 177 mg/dL \\
\hline BUN & $42 \mathrm{mg} / \mathrm{dL}$ \\
\hline Creatinine & $1.03 \mathrm{mg} / \mathrm{dL}$ \\
\hline Alb & $1.4 \mathrm{~g} / \mathrm{dL}$ \\
\hline $\mathrm{Na}$ & $131 \mathrm{mEq} / \mathrm{L}$ \\
\hline K & $4.9 \mathrm{mEq} / \mathrm{L}$ \\
\hline $\mathrm{Cl}$ & 99 mEq/L \\
\hline \multicolumn{2}{|l|}{ Serological test } \\
\hline CRP & $11.43 \mathrm{mg} / \mathrm{dL}$ \\
\hline $\lg G$ & 1195 mg/dL \\
\hline $\lg A$ & $248 \mathrm{mg} / \mathrm{dL}$ \\
\hline $\lg M$ & $93 \mathrm{mg} / \mathrm{dL}$ \\
\hline C3 & $98 \mathrm{mg} / \mathrm{dL}$ \\
\hline C4 & $24 \mathrm{mg} / \mathrm{dL}$ \\
\hline Anti-nuclear Ab & $80 \mathrm{~T}$ \\
\hline Beta2 microglobulin & $9.3 \mathrm{mg} / \mathrm{dL}$ \\
\hline Rheumatoid factor & 83 \\
\hline Cryoglobulin & Negative \\
\hline MPO-ANCA & $112.0 \mathrm{U} / \mathrm{mL}$ \\
\hline PR3-ANCA & Negative \\
\hline ASO & $33 \mathrm{IU} / \mathrm{mL}$ \\
\hline \multicolumn{2}{|l|}{ Coagulation } \\
\hline Prothrombin time (\%) & $19.90 \%$ \\
\hline PT-INR & 1.91 \\
\hline APTT & $35.2 \mathrm{~s}$ \\
\hline Fibrinogen & $631 \mathrm{mg} / \mathrm{dL}$ \\
\hline FDP & $59.9 \mathrm{ug} / \mathrm{nL}$ \\
\hline
\end{tabular}

Table 1 The data of blood and urinary sediment examination at the nephrology referral (Continued)

\begin{tabular}{ll}
\hline Endocrinology & \\
Thyroid-stimulating hormone & $3.29 \mathrm{ulU} / \mathrm{mL}$ \\
Free triiodothyronine 3 & $1.12 \mathrm{pg} / \mathrm{mL}$ \\
Urinalysis & \\
Urine-protein (qualitative analysis) & $1+$ \\
Urine-protein/urine-creatinine & 1.45 \\
Occult blood & $2+$ \\
Urine-sugar & - \\
Erythrocytes (hematuria) & $10-19 / \mathrm{HPF}$ \\
Leukocyte & $1-4 / \mathrm{HPF}$ \\
Squamous epithelial cell & $5-9 / \mathrm{HPF}$ \\
Granular cast & $1-9 / \mathrm{LPF}$ \\
Hyaline cast & $1-9 / \mathrm{WF}$ \\
FENa (\%) & $1.90 \%$ \\
FEUN (\%) & $50 \%$ \\
\hline AST aspatte aming
\end{tabular}

AST aspartate aminotransferase, $A L T$ alanin aminotransferase, $L D H$ lactate dehydrogenase, $C K$ creatinine kinase, $B U N$ blood urea nitrogen, $C R P$ C-reactive protein, MPO-ANCA perinuclear anti-neutrophil cytoplasmic antibody, PR3-ANCA cytoplasmic anti-neutrophil cytoplasmic antibody, ASO anti-streotolysin O antibody, PT-INR prothrombin time-international normalized ratio, APTT activated partial thromboplastin time, FDP fibrin degradation product, FENa fractional exertion of sodium, FEUN fractional exertion of urea nitrogen

normal that the level of serum creatinine was $0.56 \mathrm{mg} / \mathrm{dL}$ and serum blood urea nitrogen (BUN) was $13.9 \mathrm{mg} / \mathrm{dL}$ at this time. Her symptoms did not improve, and she was admitted to hospital, where she was diagnosed with infection and administered antibiotics but without effect. Two weeks later, by experiencing progressive deterioration in renal function with an increased serum concentration of myeloperoxidase-anti-neutrophil cytoplasmic antibody (MPO-ANCA), she was suspected as MPA and referred to the nephrology unit.

Physical examination showed her body temperature was $37.0{ }^{\circ} \mathrm{C}$, her blood pressure was $160 / 100 \mathrm{mmHg}$, and her pulse was 98 beats/min and regular. She had clear consciousness but experienced motor and sensory paresis and pitting edema of the arms and legs. No remarkable findings were observed in her chest and abdomen, although she complained of right back pain. Laboratory tests revealed an increased white blood cell count of $18,200 / \mu \mathrm{L}$ and anemia with $8.6 \mathrm{~g} / \mathrm{dL}$ hemoglobin. The serum level of creatinine was $1.03 \mathrm{mg} / \mathrm{dL}$. Her blood urea nitrogen (BUN) was elevated at $42 \mathrm{mg} / \mathrm{dL}$, her C-reactive protein (CRP) was $11.43 \mathrm{mg} / \mathrm{dL}$, and her MPO-ANCA was 112.0 EU. Prothrombin time (PT)-INR was 1.91 , fibrinogen was $631 \mathrm{mg} / \mathrm{dl}$, and activated partial thromboplastin time (APTT) was 35.2. Urinalysis showed proteinuria, microscopic hematuria, renal tubular epithelial cells, and granular casts (Table 1). Bacterial culture of her pharynx, expectorate, and blood revealed no significant findings. 


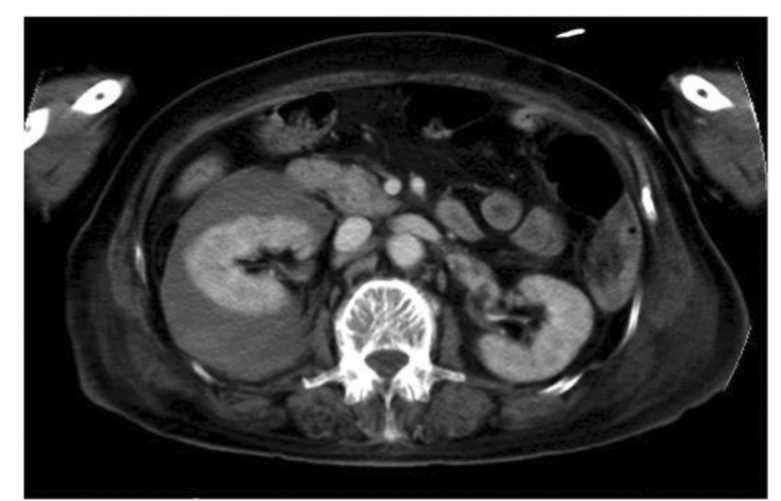

Fig. 1 Abdominal enhanced CT imaging of a subcapsular hematoma of the right kidney on day 1

Abdominal computed tomography (CT) on the day of referral to the nephrology unit showed a subcapsular hematoma of the right kidney (Fig. 1), which had not been apparent on the last CT image obtained before referral to the unit. We diagnosed her with rapidly progressive glomerulonephritis by an experiencing progressive deterioration in renal function with presence of proteinuria, microscopic hematuria, and cellular casts. A renal biopsy could not be done because of perirenal hematoma, so it was impossible to histologically diagnose. However, she was fulfilled with probable MPA, so we decided to treat her with $30 \mathrm{mg} /$ day of PSL on the ninth day after referral. On day 10, however, she complained of left back pain. Abdominal CT and ultrasonography showed bilateral perirenal hematomas (Fig. 2a, b) and laboratory testing revealed severe anemia with a hemoglobin concentration of $7.2 \mathrm{~g} / \mathrm{dL}$. On days 21 and 22 , she underwent hemodialysis because her serum concentrations of creatinine $(2.70 \mathrm{mg} / \mathrm{dL})$ and BUN (128 mg/dL) had increased; however, her CRP level normalized after she was started on PSL (Fig. 3a, b). After that, her renal function became better and hemodialysis was terminated by decrease in activity of vasculitis. On day 37, the dosage of PSL was reduced to $27.5 \mathrm{mg} /$ day, CT showed that hematoma had not increased in size, and her hemoglobin level was increasing. On day 49, her renal function became better (serum level of creatinine was $1.83 \mathrm{mg} / \mathrm{dL}$ and BUN was $50 \mathrm{mg} / \mathrm{dL}$ ) and she was transferred to the previous hospital.

\section{Discussion}

In this case, we concluded that her experiencing progressive deterioration in renal function was caused by rapidly progressive glomerulonephritis (RPGN) because of the following reasons. There was a finding of nephritis in her urinalysis analysis, and no evidence of postrenal failure in the enhanced abdominal CT. And the fractional excretion of sodium (FENa) and fractional excretion of urea nitrogen (FEUN) proved that her renal failure was not due to a prerenal cause. Moreover, although the worsening of her renal function might be caused by perirenal hematoma, there is a report that renal function was not worse in renal hematoma due to tumor, which did not affect in glomeruli [2]. RPGN and MPO-ANCA-positive suspected MPA in this patient. Definite MPA is diagnosed by the existence of both RPGN and pulmonary complications or definitive histopathological changes in a target organ. Renal biopsy was necessary to diagnose this patient as definite MPA. However, we decided not to perform renal biopsy in this patient whose right kidney had perirenal hematoma at the time of referral to the nephrology unit because renal biopsy in the right kidney had a high risk of induction of retroperitoneum hemorrhage and renal biopsy in the left kidney could not be done caused by equal in single kidney. Then, we diagnosed her as probable MPA and the worsening of her renal function was thought to be caused by probable MPA. Indeed, her renal function

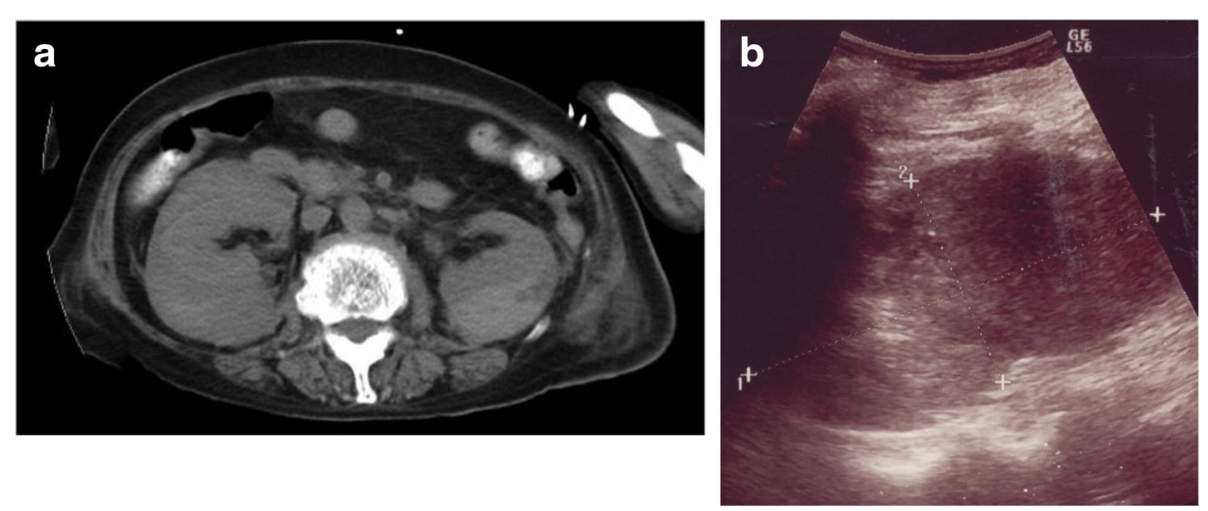

Fig. 2 Abdominal CT imaging and ultrasonography on day 10. a Abdominal CT imaging of bilateral perirenal hematomas on day 10. The density area in front of vertebral bone was the intervertebral disc and the iliopsoas muscle. These were also found in another slice of first abdominal CT. b The photograph of ultrasonography of the left kidney on day 10 


\section{a \\ PSL 30mg/day $\quad 27.5 \mathrm{mg} /$ day}
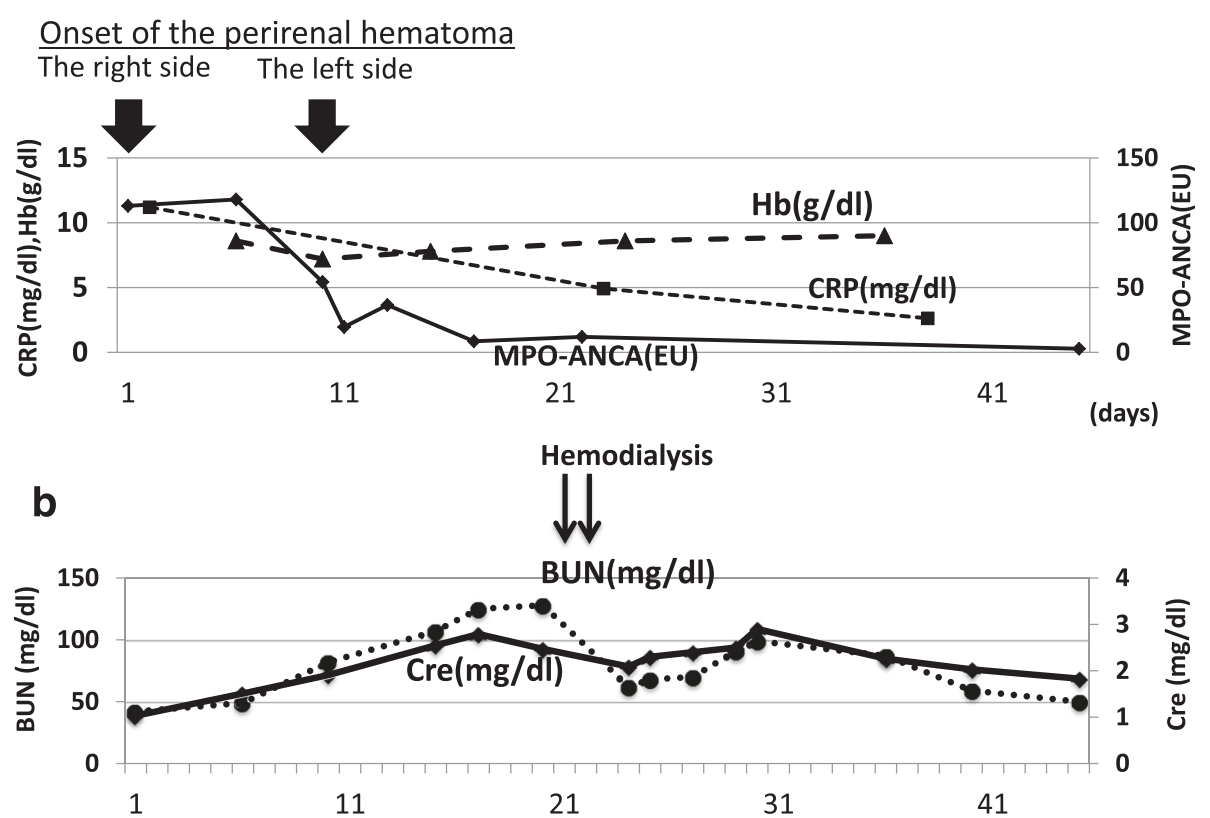

Fig. 3 Clinical course of the patient. a Change of serum levels of MPO-ANCA and CRP. $\mathbf{b}$ Change of serum levels of creatinine and BUN. PSL prednisolone, Hb hemoglobin, CRP C-reactive protein, MPO-ANCA myeloperoxidase-antineutrophil cytoplasmic antibody, Cre creatinine, BUN blood urea nitrogen

became better and hemodialysis could be terminated with the existence of bilateral perirenal hematoma by treatment for probable MPA. Her hematoma was concluded to be induced by probable MPA because an arteriovenous malformation, an aneurysm, or a kidney tumor was not found and enhanced agent was not leaked in other perirenal hematoma in enhanced CT. And the hematoma was not thought to be caused by her coagulation disorder, because her extended PT time was caused by coagulation after drawing blood due to high level of fibrinogen, which was often observed in the inflammatory diseases such as rheumatoid arthritis, and the tendency to bleed such as subcutaneous and nose hemorrhage was not observed.

Spontaneous subcapsular or perirenal hemorrhage is a relatively uncommon complication that often requires additional treatment [3, 4]. A total of 165 patients with this complication were reported between 1985 and 1999 [5]. The most common cause was benign or malignant neoplasm (101 patients, $61 \%)$, followed by vascular diseases (28 patients, $17 \%$ ). Of the latter, PN was most often reported (20 patients, $12.1 \%$ ), with other vasculitides being rare, including three patients with aneurysm, two with infarction, and one each with arteriovenous malformation (AVM), granulomatosis with polyangiitis (GPA) [4], and portal hypertension [5].

Although rare in patients with PN, spontaneous subcapsular or perirenal hemorrhage is even rarer in patients with MPA. Most reports of this complication in patients with MPA were from Japan, with the incidence being rarer in other countries. The incidence of MPA has been found to vary among countries, being higher than GPA in Asian countries, especially Japan, but very rare in western Europe and America. The clinical features of MPA and PN are similar, but MPA is rarely associated with perirenal hemorrhage. Smaller vessels are affected in MPA than in PN, reducing the volume of bleeding from affected vessels in the former and allowing blood to clot properly. Therefore, the development of a perirenal hematoma in a patient with MPA would require many blood vessels to be simultaneous affected. Furthermore, MPA was often confused with PN, but the two conditions can now be distinguished by the size of the affected vessels. Briefly, small-sized vessels are affected in MPA but not in PN. Thus, the occurrence of proteinuria or glomerular hematuria is evidence for vasculitis in a small-sized glomerular capillary. Indeed, our patient was diagnosed with MPA by the occurrence of proteinuria.

Seventeen of 20 patients with PN treated for spontaneous perirenal hematomas required angioembolization or nephrectomy, whereas the other three were cured following conservative treatment (Table 2) [6-20]. Some of these patients may actually have had MPA. Treatment of spontaneous perirenal hematomas in patients with MPA has not yet been standardized, inasmuch as only seven patients to date, including ours, have been reported with this 
Table 2 Description of patients with spontaneous perirenal hematomas and vasculitis

\begin{tabular}{|c|c|c|c|c|c|c|c|}
\hline Author & Diagnosis & Proteinuria or hematuria & $\begin{array}{l}\text { Bilatera/ } \\
\text { Unilateral }\end{array}$ & Angiogram & Embolization & Nephrectomy & $\begin{array}{l}\text { Surgical } \\
\text { treatment }\end{array}$ \\
\hline Nandwani GM et al. [6] & PN & N/A & Unilateral & Done & Done & Not done & + \\
\hline Mukhopadhyay P et al. [7] & PN & Proteinuria & Bilateral & Done & Not done & Not done & - \\
\hline Yang HC et al. [8] & PN & N/A & Unilateral & Done & Done & Not done & + \\
\hline Diaz JR et al. [9] & PN & N/A & Unilateral & Done & Done & Not done & + \\
\hline Unverdi S et al. [10] & PN & N/A & Bilateral & Done & Done & Not done & + \\
\hline Hidalgo J et al. [11] & PN & Normal & Unilateral & Done & Done & Not done & + \\
\hline Minardi D et al. [12] & PN & N/A & Unilateral & N/A & $\mathrm{N} / \mathrm{A}$ & Done & + \\
\hline Sgcan A et al. [13] & PN & Hematuria 5-6/HPF & Bilateral & Done & Not done & Not done & - \\
\hline Launay D et al. [14] & PN & N/A & Bilateral & Done & Done & Not done & + \\
\hline Schouffoer AA et al. [15] & PN & Hematuria & Unilateral & Done & Done & Not done & + \\
\hline Akcicek F et al. [16] & PN & N/A & Unilateral & Not done & Not done & Done & + \\
\hline Senaati S et al. [17] & PN & N/A & Unilateral & N/A & N/A & Done & + \\
\hline Basaranoglu M et al. [18] & PN & Proteinuria and hematuria & Bilateral & Done & Done & Not done & + \\
\hline Agarwal A et al. [19] & PN & Proteinuria and hematuria & Bilateral & Done & Done & Not done & + \\
\hline Akiko Hayakawa et al. [20] & PN & Proteinuria2+, hematuria2+ & Unilateral & Done & Done & Not done & + \\
\hline Harada M et al. [2007 $]$ & PN & N/A & Unilateral & Done & Done & Not done & + \\
\hline Tokuyama Y et al. [2001ª] & PN & Proteinuria1+, hematuria3+ & Bilateral & Done & Done & Not done & + \\
\hline Ohori K et al. [2000] & PN & N/A & Bilateral & Done & Done & Not done & + \\
\hline Kurashige T et al. [2004 $\left.{ }^{\mathrm{a}}\right]$ & PN & N/A & Unilateral & N/A & N/A & Done & + \\
\hline Kojima T et al. $\left[2009^{a}\right]$ & PN & $\begin{array}{l}\text { Proteinuria } 40 \mathrm{mg} / \mathrm{dl} \text {, } \\
\text { hematuria3+ }\end{array}$ & Unilateral & Not done & Not done & Not done & - \\
\hline 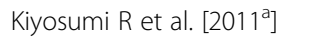 & MPA & N/A & Unilateral & Done & Done & Not done & + \\
\hline Tamei $\mathrm{N}$ et al. [21] & MPA & Proteinuria1+, hematuria2+ & Unilateral & Done & Not done & Not done & - \\
\hline Morimatsu Y et al. [22] & MPA & N/A & Unilateral & Done & Done & Not done & + \\
\hline Sakai M et al. [2009ª & MPA & N/A & Bilateral & Not done & Not done & Not done & - \\
\hline Ishikawa M et al. [2006 $\left.{ }^{\mathrm{a}}\right]$ & MPA & N/A & Unilateral & Not done & Not done & Not done & - \\
\hline Tarui $\mathrm{N}$ et al. $\left[2006^{\mathrm{a}}\right]$ & MPA & N/A & Unilateral & Done & Not done & Not done & - \\
\hline Our case & MPA & Proteiruria, hematuria & Bilateral & Not done & Not done & Not done & - \\
\hline
\end{tabular}

[ ] reference number or published year

aOnly Japanese

complication. Two patients underwent angioembolization and the other five, included our patient, were cured with conservative treatment (Table 2) [21]. These indicated that the rate of invasive treatment in PN was 0.85 (17 cases of 20 cases) and that in MPA was 0.28 (two cases of seven cases). There was significant difference between the two groupes $(P<0.01)$ using the $\mathrm{Z}$ test. Thus, invasive treatment was less necessary in patients with MPA than with $\mathrm{PN}$. Moreover, nephritis and renal failure occur more frequently in patients with MPA than PN, considering contrast-induced nephrotoxicity, the careful determination of the angiography would be needed. The rate of involvement of medium-sized arteries, which often require invasive treatment, was found to be $23 \%$ in patients with MPA [22], suggesting that small or microvessels are responsible for perirenal hematoma in patients with MPA, with no need for angioembolization. Invasive treatment in patients with MPA may be necessary for extended continuous bleeding, continuously low blood pressure, progressive anemia, or increased perirenal hemorrhage. Ultrasonography of our patient showed no evidence for increased perirenal hemorrhage. Our findings suggest that spontaneous perirenal hematomas in patients with MPA could be treated conservatively, with no signs of continuous bleeding such as continuous low blood pressure, progressing anemia, and expansion of the hematoma.

\section{Conclusions}

Because perirenal hematomas may develop in patients with MPA, differential diagnosis between MPA and PN is essential to prevent unnecessary invasive methods, such as nephrectomy or angiography, in the former. The 
presence of glomerulonephritis, which suggests involvement of smaller vessels, may be useful in differentiating between these clinically similar diseases.

\section{Consent}

Written informed consent was obtained from the patient's husband for publication of this case report and any accompanying images because she has died.

\section{Abbreviations}

AVM: arteriovenous malformation; BUN: blood urea nitrogen; CRP: C-reactive protein; CT: computed tomography; GPA: granulomatosis with polyangiitis; MPA: microscopic polyangiitis; MPO-ANCA: myeloperoxidase-anti-neutrophil cytoplasmic antibody; PN: polyarteritis nodosa; PSL: prednisolone.

\section{Competing interests}

None.

\section{Authors' contributions}

YN and MO took care of this patient. YN and TM prepared the manuscript. YN obtained written informed consent from the patient's husband. AM, MO, SN and TS participated in decision of treatment in this patient. All authors read and approved the final manuscript.

\section{Acknowledgments}

We thank Ms. M. Matsudaira and Ms. Y. Doi for their excellent secretarial support.

\section{Author details}

${ }^{1}$ Division of Nephrology, Department of Internal Medicine, Wakayama Medical University, 811-1 Kimiidera, Wakayama, Wakayama 641-8509, Japan.

${ }^{2}$ Maro Clinic, 393-5, Shimomaro, Tanabe, Wakayama 646-0004, Japan.

Received: 9 July 2015 Accepted: 7 October 2015

Published online: 18 December 2015

\section{References}

1. Jennette JC, Falk RJ, Bacon PA, Basu N, Cid MC, Ferrario F, et al. 2012 revised International Chapel Hill Consensus Conference Nomenclature of Vasculitides. Arthritis Rheum. 2013:65:1-11.

2. Frumkin J, Meigfer S. Spontaneous rupture of kidney tumors. Ann Surg. 1953:138(2):275-8.

3. Zagoria RJ, Dyer RB, Assimos DG, Scharling ES, Quinn SF. Spontaneous perinephric hemorrhage: imaging and management. J Urol. 1991;145:468-71.

4. Kendall AR, Senay BA, Coll ME. Spontaneous subcapsular renal hematoma: diagnosis and management. J Urol. 1988;39:246-50.

5. Zhang JQ, Fielding JR, Zou KH. Etiology of spontaneous perirenal hemorrhage: a meta-analysis. J Urol. 2002;67:1593-6.

6. Nandwani GM, Musker MP, Chaplin BJ, El Madhoun I, Akbani H. Spontaneous perirenal haemorrhage in polyarteritis nodosa. J Coll Physicians Surg Pak. 2013;23:445-7.

7. Mukhopadhyay P, Rathi M, Kohli HS, Jha V, Gupta KL, Sakhuja V. Polyarteritis nodosa presenting with spontaneous perirenal hematoma. Indian J Nephrol. 2012;22:295-7. doi:10.4103/0971-4065.101254.

8. Yang HC, Lee S, Kim W, Park SK, Han YM, Kang KP. Spontaneous perirenal hematoma due to multiple renal artery aneurysms in a patient with presumed polyarteritis nodosa. Vasc Med. 2012;17:427-8.

9. Diaz JR, Agriantonis DJ, Aguila J, Calleros JE, Ayyappan AP. Spontaneous perirenal hemorrhage: what radiologists need to know. Emerg Radiol. 2011; 18:329-34. doi:10.1007/s10140-011-0944-9. Epub 2011 Feb 23.

10. Unverdi S, Altay M, Duranay M, Krbas I, Demirci S, Yuksel E. Polyarteritis nodosa presenting with splenic infarction, bilateral renal infarction, and hematoma. South Med J. 2009;102:972-3.

11. Hidalgo J, Crego M, Montlleo M, de la Torre P, Bover J, Caparross J, et al. Embolization of a bleeding aneurysm in a patient with spontaneous perirenal haematoma due to Polyarteritis nodosa. Arch Esp Urol. 2005:58:694-7.

12. Minardi D, Dess-Fulgheri $P$, Sarzani R, Onesta M, Muaaj A, Branchi A, et al. Massive spontaneous perirenal hematoma and accelerated hypertension in a patient with polyarteritis nodosa. Urol Int. 2003;70:227-31.
13. Sagcan A, Tunc E, Keser G, Bayraktar F, Aksu K, Memis A, et al. Spontaneous bilateral perirenal hematoma as a complication of polyarteritis nodosa in a patient with human immunodeficiency virus infection. Rheumatol Int. 2002; 21:239-42.

14. Launay D, Michon-Pasturel U, Boumbar Y, Dubrulle F, Bouroz-Joly J, Hachulla E, et al. Bilateral spontaneous perirenal hematoma: an unusual complication of polyarteritis nodosa. Rev Med Interne. 1998;19:666-9 [French].

15. Schouffoer AA, Siegert CE, Arend SM, Thompson J, van Oostaijen JA. Embolization of a ruptured aneurysm in classic polyarteritis nodosa presenting as perirenal hematoma. Arch Intern Med. 1998;158:1466-8.

16. Akcicek F, Dilber S, Ozgen G, Ok E, Akalin E, Atabay G, et al. Spontaneous perirenal hematoma due to periarteritis nodosa. Nephron. 1994;68:396.

17. Senaati S, Cekirge S, Akhan O, Balkanci F. Spontaneous perirenal and hepatic hemorrhage in periarteritis nodosa. Can Assoc Radiol J. 1993:44:49-51.

18. Korkmaz C, Zubaroglu I, Kaya T, Akssar N, Gurbuz E, Ozen S. A case of familial Mediterranean fever, Behsset's disease and polyarteritis nodosa complicated by perirenal haematoma. Clin Exp Rheumatol. 2001;19 Suppl 24:S78-9.

19. Agarwal A, Bansal M, Pandey R, Swaminathan S. Bilateral subcapsular and perinephric hemorrhage as the initial presentation of polyarteritis nodosa. Intern Med. 2012;51:1073-6. Epub 2012 Apr 29.

20. Hayakawa A, Nakajima T, Satoh K, Yamazaki J, Zeniya M, Nasu K, et al. Case report: a case of polyarteritis nodosa with small intestinal perforation and renal aneurysm rupture. Nihon Naika Gakkai Zasshi. 2013;102:714-6 [Japanese].

21. Tamei N, Sugiura H, Takei T, Itabashi M, Uchida K, Nitta K. Ruptured arterial aneurysm of the kidney in a patient with microscopic polyangiitis. Intern Med. 2008;47:521-6.

22. Guillevin L, Lhote F, Amouroux J, Gherardi R, Callard P, Casassus P. Antineutrophil cytoplasmic antibodies, abnormal angiograms and pathological findings in polyarteritis nodosa and Churg-Strauss syndrome: indications for the classification of vasculitides of the polyarteritis Nodosa Group. Br J Rheumatol. 1996;35:958-64.

\section{Submit your next manuscript to BioMed Central and take full advantage of:}

- Convenient online submission

- Thorough peer review

- No space constraints or color figure charges

- Immediate publication on acceptance

- Inclusion in PubMed, CAS, Scopus and Google Scholar

- Research which is freely available for redistribution 